\title{
Models and Metaphors: Complexity Theory and Through-Life Management in the Built Environment
}

John Rooke, Ella-Mae Molloy, Murray Sinclair, Lauri Koskela, Mohan Siriwardena, Mike Kagioglou and Carys Siemieniuch

Published as: Rooke, J., Molloy, E. M., Sinclair, M., Koskela, L., Siriwardena, M., Kagioglou, M. \& Siemieniuch, C. (2008) 'Models and Metaphors: Complexity Theory and Through-Life Management in the Built Environment,' in Architectural, Engineering and Design Management 4(1):47-57.

\footnotetext{
Abstract

Complexity thinking may have both modelling and metaphorical applications in the through-life management of the built environment. These two distinct approaches are examined and compared. In the first instance, some of the sources of complexity in the design, construction and maintenance of the built environment are identified. The metaphorical use of complexity in management thinking and its application in the built environment are briefly examined. This is followed by an exploration of modelling techniques relevant to built environment concerns. Non-linear and complex mathematical techniques such as fuzzy logic, cellular automata and attractors, may be applicable to their analysis. Existing software tools are identified and examples of successful built environment applications of complexity modelling are given. Some issues that arise include the definition of phenomena in a mathematically usable way, the functionality of available software and the possibility of going beyond representational modelling. Further questions arising from the application of complexity thinking are discussed, including the possibilities for confusion that arise from the use of metaphor. The metaphor of a 'commentary machine' is suggested as a possible way forward and it is suggested
} 
that an appropriate linguistic analysis can in certain situations reduce perceived complexity.

Keywords - Complexity; metaphor; modelling; production theory; unique adequacy

\section{Introduction}

Companies in the construction industry have tended to manage the risks of operating in the built environment (BE) through risk transfer moderated by contracts. However, these strategies do not in themselves reduce risk and more recently there has been an increasing tendency to consider construction and its products more holistically, with trends such as partnering, including publicprivate partnerships and through-life management, coming to the fore. The increased onus on players to consider the consequences of their actions in a wider sphere leads inevitably to a greater consideration of the complexity entailed in the design, construction and maintenance of the built environment. Moreover, these trends imply that we think not simply in terms of built environment products, but of the services (such as education, healthcare and communications) that buildings and civil engineering projects support, in terms of a product-service paradigm in the built environment. This paper seeks to explore how complexity theory may help to resolve the problems of organization thus presented.

Complexity concepts can be operationalized as either modelling or metaphor. We outline some parameters for the complex system under consideration and examine the application of complexity theory to the study of business. In conclusion, we focus on a particular metaphor which indicates the possibility of specifying the details of complex settings. 


\section{Production and service in the built environment}

It is undeniable that companies and public agencies working to commission, design, build, service and maintain the built environment are operating in situations of complexity, both with regard to their environments and their internal operations. Considerations that feature in decision-making processes will include inter alia:

- fluctuations in available finance and thus effective demand

- evolving procurement and contracting strategies

- pressures to reduce costs, while improving timeliness and quality

- pressure to maintain profitability

- a range of competing initiatives to improve company performance

- differing and sometimes conflicting professional and occupational standards and loyalties

- the salience of industry-wide standards

- the need to improve safety performance and environmental sustainability

- the need to balance technological and organizational innovation against familiar and reliable methods. 
From the perspective of through-life management, a further set of problems is added:

- the predictability of future service and maintenance costs

- future demand for the services the BE feature supports

- changing techniques and technologies in the services supported by the BE feature

- changing concerns and priorities with regard to the natural environmethe acquired individual character of particular BE elements as they gain significance as local landmarks, cultural icons or historical sites.

\section{Metaphor}

Morgan (1986) asserts the importance of metaphor in understanding organizations. His claim that 'our theories and explanations of organizational life are based on metaphors' (1986: 12) may be an over-generalization. However, he is undeniably correct in identifying the metaphorical process, in which we 'understand one element of experience in terms of another' (1986: 13), as one that is important to theory making.

Several benefits of the metaphorical use of complexity thinking can be identified; for instance, the importance of connectivity and interdependence in complex systems can be used to stress the collective nature of organization. Mittleton-Kelly (2003) reiterates a common social science observation that an individual's contribution to a team is constrained by what the team will permit (Parsons, 1968; Hofstede, 2002). She also notes that the social ecosystem in which an organization 
exists consists of other organizations which both affect that organization and are affected by it. She uses the concept of exaptation to emphasize the importance of allowing an organization's members to explore the 'space of possibilities' that exists, thus encouraging lateral thinking (de Bono, 1971). Along with Gershenson and Heylighen (2005), she stresses the concepts of self-organization, feedback and attractors to describe organizational change. Thus, complexity thinking is taken primarily as a stimulus to more flexible management styles, reinforcing what has long been a trend in management studies (Peters and Waterman, 1982; Handy, 1994).

In applying such a metaphorical approach to the built environment industry, particular peculiarities may be revealed. The so-called 'fragmentation' of the industry has long been commented on (see for instance Groak, 1994). More recently, aspects of fragmentation have been addressed from a more complexity-oriented perspective. Chen et al (2007) note the difficulties presented for knowledge management in multi-organizational systems. Bresnen et al (2005) point out the dispersed nature of management in project organizations and the difficulties this creates in organizational change. They adopt situated knowledge and symbolic interaction approaches to enable them to come to grips with this phenomenon. Bertelsen and Emmitt (2005) adopt an explicit complexity approach, to view the client as a complex system.

In an examination of three complex projects, two of which involved work on major built environment features, Ivory and Alderman (2005) derive four major implications for project management. They observe that systemic contradictions are most usually expressed as resource failures. Drawing on complexity analyses that use multi-nodality and multi-centredness, they conclude that some measure of mapping and prediction of knock-on impacts can be achieved, but they also observe that to a considerable extent, management activity consists of developing reactive organizational fixes. Interventions from subordinate nodes in the supply chain can have both beneficial and negative effects. 
Drawing on the Danish Byg.SoL initiative, Bertelsen (2004) suggests a panoramic view of project management in the built environment that draws on the complexity metaphor to suggest five different ways of looking at management - planning, organizing, team building, providing a service, and causing a nuisance.

\section{Modelling}

The use of mathematical modelling techniques for simulating complex systems within the built environment is controversial (Richardson et al, 2000). Often, a prediction of the future is expected as an output from a mathematical equation. Guastello (1995) states that the 'prediction of future states is possible in the near term, but could decay rapidly as we try to extend further into the future'. Although we know that maths cannot predict the future, we are disappointed when it does not.

Non-linear and complex mathematical modelling techniques have been applied to supply chain and workforce management (Guastello, 1995) and cellular automata for the modelling of regions (Allen, 1997a). Techniques that may be useful include fuzzy logic, cellular automata, chaos theory, catastrophe theory and fractals - basic explanations of which can be found in many texts (von Neumann, 1966; Codd, 1968; Kosko, 1993; Guastello, 1995; Berry, 1996; Wolfram, 2002; Steeb, 2005). Complex techniques are rarely used in isolation (Steeb, 2005), but more often in combination with other modelling techniques. For example, non-linear dynamic systems may be linked to game theory to investigate long-range planning and reactive management in the construction trades (Guastello, 1995). Fuzzy logic helps to explain the shades of grey in between the black and white of many established techniques.

Some suggest that while complex systems need not follow traditional modelling techniques, complex phenomena do not always need complex theory to explain them; complexity can emerge from simple beginnings (Wolfram, 2002). 
There is much literature on agent-based models, multi-agent systems and Complex Adaptive Systems theory (the latter term originating from the work of John Holland and others at the Santa Fe Institute ) (Carroll and Burton, 2000; Dijkstra et al, 2001; Shen et al, 2001; Seese and Schlottmann, 2003; Payr and Trappl, 2004; Robertson, 2005; McCarthy et al, 2006). These can demonstrate complex nonlinear interactions that allow the emergence of new unpredictable properties in the system, allowing flexibility and a network-based interaction representation of built environment systems. Many focus on 'software agents', ignoring the special characteristics of human agents, but may still be useful to model teams, processes and organizations, for example. Agent-based models, such as Conway's Game of Life (Gardner 1970), have been in widespread use for around a decade.

Agent-based software programs available on the Internet include StarLogo (http://education.mit.edu/starlogo/) and JADE (http://jade.tilab.com). StarLogo is a basic programmable modelling environment for exploring the workings of decentralized systems (there is also an extension StarLogo TNG). It is designed as an introduction for students and researchers and has a colourful and usable interface. JADE (Java Agent DEvelopment Framework) is a software framework to develop agent-based applications, but seems to assume that agent = software agent, limiting its application to organizational systems.

MATLAB ${ }^{\circledR}$ (www.mathsworks.com) is a high-level technical computing language and interactive environment for algorithm development, data visualization, data analysis and numeric computation. The many add-ons (toolboxes) it contains allow for flexibility in analysis and simulation. At its basic level, MATLAB allows for the development of agents and their environment, while the toolboxes provide a wider range of application and accuracy.

Increasingly complex construction projects mean that the problems of uncertainty and ambiguity have ever larger implications because of the difficulty in predicting the impact of unexpected changes. 
Particularly promising fields for this endeavour appear to be economics and geography (Arthur, 1990, 1995; Allen, 1997a, 1997b [Q5]), both of which are important to built environment concerns.

Consideration of different aspects of design, such as environment, economy and society, in addition to the traditionally considered characteristics, makes the problem of design more complex. It has been suggested in the built environment context that mathematical techniques, such as fuzzy logic (Boussabaine and Elhag, 1999; Vakili-Ardebili and Boussabaine, 2007), stochastic approaches (Kirkham and Boussabaine, 2005) or neural networks (Boussabaine, 1996) may be useful, or even essential, to assist decision-makers. It is perceived that such techniques may aid circumnavigation of the subjectivity in design decisions, especially in modern challenges, such as ecological/sustainability concerns (Vakili-Ardebili and Boussabaine, 2007) and that these tools are becoming more accessible to non-computer specialists. Areas where the techniques have been applied include an approach to forecasting the remaining life of hospital buildings and optimization of maintenance strategies (Kirkham and Boussabaine, 2005); minimizing production time, achieving optimum mark-up estimation under different bid situations, predicting changes in construction cost indexes, estimating excavation efficiency based on attributes of operation elements and decision-making about construction modularization (Boussabaine, 1996); and cash flow (Boussabaine and Elhag, 1999).

The application of mathematical tools outlined above has generally been found to be useful, but they are underused because construction managers do not understand the mathematical processes by which the results are achieved. It may be possible to input a set of data and generate a suggested configuration, but without an understanding of the mathematical operations involved, it is difficult to have confidence in the outputs.

Another starting point for mathematical modelling may be found in the use of flow theory (Koskela, 1992, 2000). The application of flow theory in the built environment has led to useful developments such as the Last Planner (Ballard and Howell, 1998; Ballard, 2000) and the ADePT tool (Austin et al, 
1994). However, notwithstanding the successful application of both these approaches (Thomassen $e t$ al, 2003; Baldwin et al, 2008) they do not represent the application of either sophisticated mathematics or modelling techniques. The Last Planner system is a management system that introduces flexibility and ultimately reliability into the planning system by shifting the locus of control down the management hierarchy and closer to the actual activity of production (Ballard and Howell, 1997a, 1997b). ADePT utilizes a dependency structure matrix (Austin et al, 1994, 2000) to rationalize the ordering of design tasks. One of the central phenomena of interest to flow theorists is that of queues (both Last Planner and ADePT address problems of queuing, although in radically different ways). Although queuing theory has been applied to factory production (Hopp and Spearman, 2001), built environment processes are arguably more complex. Nonetheless, work is under way towards identifying critical flows that may ultimately be amenable to mathematical analysis and modelling (Bertelsen et al, 2006, 2007).

It is worth noting that modelling applications have much in common with metaphors. If we accept that, whatever their basis, models represent simplifications of a system, then models are not so different from metaphors, which at their core are meant to be symbolic representations of something else. Indeed models (and diagrams) are aids to solving problems, not solutions in themselves. Thus, another way of viewing the work of Mittleton-Kelly (2003) or Gershenson and Heylighen (2005) is as outlining the concepts necessary to the creation of such models.

\section{Simple complexity and complicating simplicity}

However, in some cases, the appearance of complexity may be generated by the inadequacy of our (non-mathematical) analytic methods. This can be one consequence of treating human organizational phenomena as amenable to exhaustive causal analysis. The use of mental terms (for example, disposition terms such as mood, attitude, personality, culture) in a non-causal analysis can provide simpler formulations. Moreover, metaphors can be misleading and it is worth looking more closely at 
how they are used in practice, i.e. in what ways they help, how they break down and with what consequences. For instance, Gershenson and Heylighen (2005) use the metaphor of complexity to attempt an escape from the restrictive bonds of Cartesian thought:

"From the cybernetic perspective, there is no strict boundary between the 'material' and the 'mental' components: the information stored in my notebook is as much a part of my memory as is the information stored in my brain, and my email connection is as much part of my communication equipment as the nerves that control my speech.” (Gershenson and Heylighen 2005: 56)

However, the new conceptual space created is relatively minor, compared with that achieved by phenomenological and linguistic philosophers (Wittgenstein, 1958; Schutz, 1962; Ryle, 1963). Thus, they find it necessary to resort to the Cartesian dualism of a universal objective reality and local subjective perception, in order to explain differences in perception. This, in turn, allows them to cling to the familiarity of a clockwork Newtonian universe, comforting though concealed, but it leaves the residual problem of how objective (physical) reality is to be reconciled with subjective (mental) perception (Button et al, 1995). There is a vast literature on this problem, which has proved an intractable theoretical inconvenience. It is most easily removed by recognizing that a) objectivity is itself a local achievement by situated perceptive beings and that $b$ ) the relaxation of distinctions is a linguistic move, rather than an ontological discovery.

The concept of dissipative structures may also be misleading. Although history is an important consideration in human systems, it would seem that complexity thinking has little to offer to an already highly developed field. In directing attention to the relatively impoverished concept of history employed in chemistry, Mittleton-Kelly (2003) runs the risk of overlooking the rich analysis that already exists in the sociological (Weber, 1976; Parsons, 1951) and management traditions (e.g. Kanter, 1985). 
Wolfram's (2002) discovery that computer programs operating simple rules can generate highly complex patterns provides for an ambiguity in the description of such programs. Viewed as sets of rules, the programs may be described as simple; viewed as generators of outcomes, they may be described as complex. (Note also that the rules look simple because of the way they are stated, using boxes (Wolfram, 2002: 27) they would no doubt look more complicated if stated exclusively in English.) It is apparent that the perception of complexity depends on how a given mathematical phenomenon is viewed. Using the metaphor of the disturbances produced by two speedboats whose paths continuously interweave on an otherwise placid sea, Burke (1969) explicated such a phenomenon with regard to human behaviour; the complex or chaotic outcomes can be seen as the interaction of only two elements. The fact that complexity can be simple is confirmed by Gershenson and Heylighen (2005) who state that complexity can consist of as little as two parts. Sacks (1972) made a similar observation, speculating that it may not be that human behaviour is complicated that makes it so baffling to social scientists, but the fact that human behaviour is self-characterizing.

Sacks (1963) had previously employed the elaborate metaphor of a 'commentary machine' to illustrate the problem of social research. This machine functions to produce a commentary on its own activities. These are observable and in principle describable by social scientists, but these descriptions have the same ontological status as the descriptions produced by the machine itself. Indeed, they are often descriptions of descriptions. This presents problems related to both, i.e. how naturally produced descriptions are to be scientifically treated, and the nature of the claims that can be made for social scientists' own descriptions. The working out of these conundrums has been one source of the principle of unique adequacy (UA) discussed below. Note that the two parts here are the scientist (observer) and the subject (observed) - the complexity is in the relationship between them. It would be mistaken to believe that the two parts are, for instance, the action and its self-characterization, as Ryle's (1963) critique of Cartesianism clearly shows. 
Snowden's Cynefin framework (Snowden, 2002; Kurtz and Snowden, 2003) is, among other things, an attempt to avoid such inappropriate categorizations of the world. Rather than categorizing the world directly, it offers a categorization of ways of looking at the world, with the additional proviso that the category boundaries are permeable and flexible. Thus, Cynefin provides a tool for achieving negotiated order (Strauss et al, 1964). Such tools provide a means of both understanding and creating systems in which:

"the possibility that interactions between large numbers of entities, each entity responding to others on the basis of its own local organizing principles, will produce coherent patterns with the potential for novelty in certain conditions." (Stacey, 2001: 93)

It may be that reaching such an understanding depends upon conducting research to meet the UA requirement of methods (Garfinkel and Wieder, 1992; Garfinkel, 2002). Livingston (1987) illustrates the significance of this requirement with reference to the patterns of movement formed by crowds crossing the road at a busy intersection. Overhead videotape footage reveals that crowds typically make wedge-shaped formations. There would seem to be three alternative strategies for answering the question as to how these formations are generated:

- use the videotape material to take an overview of the whole system and analyse the flows as they occur to determine possible chains of causality

- analyse the behaviour of single entities in order to discover their local organizing principles. This second course is clearly appropriate to complex systems

- however, for human systems, a third possibility exists. We may interview participants in crowds, or participate in crowds ourselves, in order to obtain an inside view of how the 
patterns are generated. In this way, the decisions of the crowd's members provide an additional rich source of whose complexity the UA requirement is designed to address.

It is noticeable that complexity-oriented scholars in the built environment have, to varying degrees, adopted this third strategy, the analysis of perceptions from particular identified points of view (Smallwood, 2000; Bertelsen 2004; Bertelsen and Emmitt 2005; Bresnen, Goussevskaia and Swan 2005; Elhag, Boussabaine and Ballal 2005).

The UA requirement has two forms, both of which:

"are founded on the principle that the activities and procedures of persons in a setting can best be accounted for in terms of the understandings that those persons have of that setting. Thus, the task of the ethnographer is to render a clear description of those understandings, rather than offer an explanatory theory." (Rooke et al, 2004: 656)

In its weak form, the UA requirement demands that 'the analyst must be vulgarly competent in the local production and reflexively natural accountability of the phenomenon' (Garfinkel and Wieder, 1992: 182). Thus, to analyse a decision-making process adequately, we must know what any participant in the process would ordinarily know about that process. This knowledge, expressed as competence, is the kind referred to by Ryle (1963) as 'knowing how'. In this form, the requirement is proposed as a criterion for adequate ethnography, the most certain method for acquiring such knowledge being participant observation. However, it is possible to usefully apply it to other forms of enquiry, such as interviews and questionnaires. Thus, for instance, a questionnaire designed by someone who had no direct knowledge of the process under study is likely to contain irrelevant, misleading or even meaningless questions. 
$<$ body text $>$ The strong requirement concerns the reporting of research. It demands that the methods of analysis used to describe a process should be derived directly from that process. This assumes that the methods that participants use in the process of making a decision are sufficient to the purpose of producing an account of that decision. It is proposed as a standard for the description of any phenomenon which is composed of (and by) conscious beings who are able to produce an account of their own activities. It is proposed that methods of analysis that are alien to the analysed setting (thus introducing a theoretical spin to the description) must involve some distortion. This requirement is proposed as a criterion for ethnomethodology. However, reports have been written outside this discipline which, at least in part, meet this form of the requirement (e.g. Dutton and Starbuck, 1971). It currently informs much of the work being done in the field of Computer Supported Co-operative Work (CSCW). For instance, Button and Sharrock (2002) have offered a UA description of the routine decision-making processes of a production scheduler in a print works.

Intrinsic complexity could be said to lie in several areas of the activity, for instance, the craft-like nature of the printing process; variability in the capability and performance of printing machines; conflicts between the technology used by the design house customers and the ability of the printing equipment to replicate this. Intrinsic complexity could also be seen to be inherent in the relationships between the customer and the printers, since these are taken as a given, although actual instantiations of uncertainties and 'buggeration' factors may vary from case to case.

Induced complexity would seem to emanate from the nature and variability of the work-breakdown structures within the printing organization; the relationships between the various roles of e.g. account holder, scheduler, shop floor personnel, management; the range and depth of both the formal and tacit knowledge and experience of the individual scheduler; the variation and evolution of organizational units from job to job and shift to shift. 
Decision-making in this context is affected by both the above and by certain elements of what could be called 'emergent behaviour' or 'system interoperability'. The former, because any combination of type of job, different team, different shift, different machines, degree of foreseeable problems, etc. will result in a potential event (e.g. job stopped, job delayed, etc.) which will require decisions to be made on the schedule to be regularly revisited in a partially structured ad hoc manner. The latter, because the overall printing capability is not an integrated or interoperable system and perhaps, given its nature, could never be. In a sense, the scheduler functions to integrate the system, often acting on the fly. It is not clear how much of the decision-making process is repeated in terms of process, variables taken into account, and people consulted. By this we mean: does a set of decision-making processes and variables come into play for similar sets of problems, or is it a totally random process that varies from scheduler to scheduler?

Although no similar studies exist as yet of the design, construction or maintenance of the built environment, there are many parallels that may be drawn. For instance, the role of the scheduler as an absorber of inter-task complexity is highly relevant to the sometimes seemingly intractable problems of co-ordination on construction projects. Some key decision-making techniques are:

- to eliminate the need to consider alternatives (although possibly holding these in reserve) by producing a single workable schedule

- to simplify the interactions between tasks to a smaller set of known ones (while possibly retaining others mentally)

- to leave intra-task complexities, that will take effect once the task commences, and may, via the inter-task interactions, affect other tasks, to be fixed by the task operators [Q20ok], based on their knowledge and experience. 


\section{Conclusion}

We have identified two forms of complexity thinking - metaphor and modelling. The immediately apparent use of metaphor in the examples we have considered is rhetorical, as suits the use of a poetic device. Complexity metaphors can be used to call attention to important features of organization and to advocate particular styles of management.

We have observed that the modelling form is sometimes mistakenly thought to enable prediction. It should rather be thought of as a means of exploring possibilities, particularly those that would otherwise not be apparent.

We have also noted what models and metaphors have in common - both are forms of analogy. Whereas metaphor offers a direct comparison between phenomena found in the world (such as an organization and a machine), a model constitutes a deliberately simplified representation of a phenomenon. Thus, models are a way of relating mathematical techniques to actual existing systems - we have identified several applications both in the built environment and more widely.

The two approaches offer very different resources for tackling a problem. The model, through simplification, may help us to identify the important or essential features of a system, excluding obfuscating detail. By contrast, a metaphor adds something new, enriching our understanding to provide a further possibility of creative solution. The model may be said to sharpen our focus, the metaphor to broaden it. Together, they can form a bridge for the introduction of complex mathematical techniques. Metaphors may provide a common ground for explanation of the maths $-\mathrm{a}$ common practice in mathematical education. Models are necessary to reduce a phenomenon to a mathematically analysable form.

However, we must not forget that a solution to a maths problem is simply that. Its applicability to the 
real world depends on the constitution of the models we have built. And complexity theory tells us that patterns can emerge where we least expect them. We must be sure we are clear about the questions we are asking and must be cautious in our assumptions that we have identified the important variables. We should bear in mind that, as yet, the most successful applications of flow theory in the management of design and construction processes - the Last Planner and ADePT tools have a limited mathematical content.

Furthermore, it is important to accept and understand that different people have different mental models and, as such, will view metaphors in different ways. We have noted some ways in which applications of complexity theory to organizational analysis may be misleading. It is important in avoiding these pitfalls that we consider the ways in which complexity is being used. The notion of history, for instance, may be important in identifying a quality of systems that it may then be possible for mathematicians to model. It is hardly likely in itself to add anything to social science understanding.

Finally, we have considered a metaphor arising not from complexity theory, but from social science. The metaphor of the commentary machine leads us away from rhetoric, towards specification of the actual psycho-social processes that constitute the stuff out of which real-life organizations are built. We have shown how reports of such specifications can reveal actual features of complex organizational settings.

\section{Acknowledgements}

This paper was written under the aegis of the Knowledge and Information Management (KIM) Through-Life Grand Challenge Project (www.kimproject.org) funded primarily by the Engineering and Physical Sciences Research Council (EPSRC - Grant No. EP/C534220/1), the Economic and Social Research Council (ESRC - Grant No. RES-331-27-0006), Loughborough University's Innovative Design and Manufacturing Research Centre (IMRC - Grant No. EP/E002323/1) and 
SCRI, Salford University's Innovative Design and Manufacturing Research Centre (IMRC - Grant No. EP/E001882/1).

\section{Author contact details}

John Rooke: j.a.rooke@eml.fm

SCRI, Institute for Research in the Built and Human Environment, School of the Built Environment, University of Salford, $4^{\text {th }}$ Floor, Maxwell House, The Crescent, Salford M5 4WT. Telephone 0161 295 6344. Fax 01612954587.

Lauri Koskela: e-mail: L.J.Koskela@salford.ac.uk

Mohan Siriwardena: e-mail: mohansiri@yahoo.com

Ella-Mae Molloy: e-mail: E.Molloy @lboro.ac.uk

Carys Siemieniuch: e-mail: $\underline{\text { C.E.Siemieniuch@ @lboro.ac.uk }}$

Murray Sinclair: e-mail: M.A.Sinclair@lboro.ac.uk

Mike Kagioglou: e-mail: m.kagioglou@ salford.ac.uk

\section{References}

Allen, P.M., 1997a, Cities and Regions as Self Organising Systems, Vol 1, Gordon and Breach, Amsterdam.

Allen, P.M., 1997b, 'Cities and regions as evolutionary, complex systems,' in Geographical Systems, 4(1):103-130.

Arthur, B.W., 1990, 'Positive feedback in the economy', in Scientific American, 80(1):92-99.

Arthur, B.W., 1995, Increasing Returns and Path Dependence in the Economy, University of Michigan Press, Ann Arbour. 
Austin, S., Baldwin, A., Baizhan, L.I. and Waskett, P., 2000, 'Analytic design planning technique (AdePT): a dependency structure matrix tool to schedule the building design process', in Construction Management and Economics 18(2):173-182.

Austin, S., Baldwin, A. and Newton, A., 1994, 'Manipulating the flow of design information to improve the programming of building design', in Construction Management and Economics, 12(5):445-455.

Baldwin, A.N., Shen, L.Y., Poon, C.S., Austin, S.A. and Wong, I., 2008, 'Modelling design information to evaluate pre-fabricated and pre-cast design solutions for reducing construction waste in high rise residential buildings, ' in Automation in Construction, 17(3):333-341.

Ballard, G., 2000, The Last Planner System of Production Control, PhD thesis, School of Civil Engineering, Faculty of Engineering, The University of Birmingham, UK, http://www.leanconstruction.org/pdf/ballard2000-dissertation.pdf

Ballard, G. and Howell, G. 1997a, 'Implementing lean construction: stabilizing work flow', in L. Alarcon (ed), Lean Construction, Rotterdam, A.A. Balkema, 101-110. Paper originally presented (1994) at the International Seminar on Lean Construction, Edefica, Pontificia, Universidad Catolica, Santiago de Chile.

Ballard, G. and Howell, G., 1997b, 'Implementing lean construction: improving downstream performance', in L. Alarcon (ed), Lean Construction, Rotterdam, A.A. Balkema, 111-126.

Ballard, G. and Howell, G., 1998, 'Shielding production: essential step in production control', in Journal of Construction Engineering and Management, 124(1):11-17. 
Berry, J.S., 1996, Introduction to Non-Linear Systems, London, Arnold.

Bertelsen, S., 2004, 'Construction management in a complexity perspective', in Aouad, G., Amaratunga, D., Kagioglou, M., Ruddock, L. and Sexton, M. (Eds.) Proceedings of the first international SCRI symposium, March, Salford Centre for Research and Innovation (SCRI) in the Built and Human Environment, University of Salford, 346 - 355.

http://www.bertelsen.org/strategisk r\%E5dgivning aps/pdf/Salford\%202004.pdf

Bertelsen, S. and Emmitt, S., 2005, 'The client as a complex system', in First, I. (Ed.) Proceedings of the 13th Annual Conference of the International Group for Lean Construction, International Group for Lean Construction, Sydney, Australia, 73-80, ISBN: 18-7704-034-7

http://www.iglc.net/conferences/2005/papers/

Bertelsen, S., Henrich, G., Koskela, L. and Rooke, J., 2007, 'Construction physics', in C. L. Pasquire, \& P. Tzortzopoulos (Eds.) Proceedings of the 15th Annual Conference of the International Group for Lean Construction, Michigan State University, East Lansing, 13-26.

http://www.iglc.net/conferences/2007/folder.2007-06-29.2095743756/

Bertelsen, S., Koskela, L., Henrich, G. and Rooke, J., 2006, 'Critical flow; towards a construction flow theory', in C. Pasquire \& P. Tzortopoulos (Eds.) Proceedings of the 14th Annual Conference of the International Group for Lean Construction, July, Pontificia Universidad Católica de Chile, Santiago de Chile, 31-40, http://www.iglc2006.cl/papers.html

Boussabaine, A.H. and Elhag, T., 1999, 'Applying fuzzy techniques to cash flow analysis', in Construction Management and Economics, 17(6):745-755.

Boussabaine, A.H., 1996, 'The use of artificial neural networks in construction management: a 
review', in Construction Management and Economics, 14(5):427-436.

Bresnen, M., Goussenvskaia, A. \& Swan, J. (2005) 'Organizational routines, situated learning and processes of change in project-based organizations,' in Project Management Journal, 36(3):27-41.

Burke, K., 1969, A Grammar of Motives, London, University of California Press.

Button, G. \& Sharrock, W. 2002, 'Operating the production calculus: ordering a production system in the print industry', in British Journal of Sociology, 53(2):275-289.

Button, G., Coulter, J., Lee, J.R.E. and Sharrock, W.W., 1995, Computers Minds and Conduct, Cambridge, Polity Press.

Carroll, T. \& Burton, R. M. 2000, 'Organisations and complexity: searching for the edge of chaos', in Computational and Mathematical Organisation Theory, 6(4):319-337.

Chen, J., Taong, L. and Ngai, E.W.T., 2007, 'Inter-organizational knowledge management in complex product systems: challenges and an exploratory framework', in Journal of Technology Management in China, 2(2):134-144.

Codd, E.F., 1968, Cellular Automata, New York and London, Academic Press.

de Bono, E., 1971, The Use of Lateral Thinking: Break the Stranglehold of Logical Thinking, Harmondsworth, Penguin. 
Dijkstra, J., Jessurun, J. and Timmermans, H. 2001, 'A multi-agent cellular automata model of pedestrian movement', in M. Schreckenberg and S.D. Sharma (eds), Pedestrian and Evacuation Dynamics, Berlin, Springer-Verlag, ISBN: 3-540-426-906, 173-181.

Dutton, J.M. \& Starbuck, W. 1971, ‘Finding Charlie’s run-time estimator', in J. M. S. Dutton \& W. Starbuck (Eds.) Computer Simulation of Human Behaviour, Wiley, Chichester, 218-242.

Elhag, T. M. S., Boussabaine, A. H. \& Ballal, T. M. A. (2005) 'Critical determinates of construction tendering costs: quantity surveyors' standpoint,' in International Journal of Project Management, 23(7):538-545.

Gardner, M, 1970, 'The fantastic combinations of John Conway's new solitaire game "life"', in Scientific American, 233:120-123.

Garfinkel, H., 2002, Ethnomethodology's Program: Working out Durkheim's Aphorism, Lanham, Rowman and Littleford.

Garfinkel, H., Wieder, D. L. 1992, ‘Two incommensurable, asymmetrically alternate technologies of social analysis', in G. Watson \& R. M. Seiler (Eds.) Text in Context, London, Sage, 175-206.

Gershenson, C.H. \& Heylighen, F. 2005, 'How can we think complex?', in K. A. Richardson (Ed.) Managing Organizational Complexity: Philosophy, Theory and Application, Information Age Publishing, 47-61.

Groak, S., 1994, 'Is construction an industry? Notes towards a greater analytic emphasis on external 
Models and Metaphors 2008 Rooke, Molloy, Sinclair, Koskela, Siriwardena, Kagioglou, Siemieniuch

linkages', in Construction Management and Economics, 12(2):287-293.

Guastello, S.J., 1995, Chaos, Catastrophe and Human Affairs: Applications of Nonlinear Dynamics to Work, Organisations and Social Evolution, Mahwah, New Jersey, Lawrence Erlbaum Associates.

Handy, C., 1994, The Empty Raincoat: Making Sense of the Future, London, Hutchinson.

Hofstede, G., 2002, Culture's Consequences: Comparing Values, Behaviours, Institutions and Organizations Across Nations, London, Sage.

Hopp, W.J. and Spearman, M.L., 2001, Factory Physics, New York, McGraw-Hill.

Ivory, C. \& Alderman, N. (2005) 'Can project management learn anything from studies of failure in complex systems?' in Project Management Journal, 36(3):5-16.

Kanter, R.M., 1985, The Change Masters: Corporate Entrepreneurs at Work, London, Unwin.

Kirkham, R.J. and Boussabaine, A.H., 2005, 'Forcasting the residual service life of NHS hospital buildings: a stochastic approach', in Construction Management and Economics, 23(5):521-529.

Koskela, L., 1992, Application of the New Production Philosophy to Construction, Technical Report No 72, Center for Integrated Facility Engineering, Stanford University, California.

Koskela, L., 2000, An Exploration towards a Production Theory and its Application to Construction, VTT Publication 408, VTT Technical Research Centre of Finland.

Kosko, B., 1993, Fuzzy Thinking - The New Science of Fuzzy Logic, 1st edn, London, Flamingo. 
Kurtz, C.F. \& Snowden, D. J. 2003, 'The new dynamics of strategy: sense-making in a complex and complicated world', in IBM Systems Journal, 42(3):462-483.

Livingston, E., 1987, Making Sense of Ethnomethodology, London, Routledge and Kegan Paul.

McCarthy, I., Tsinopoulous, C, Allen, P, Rose-Anderssen, C. 2006, 'New product development as a complex adaptive system of decisions', in Journal of Product Innovation Management, 23(5):437456.

Mittleton-Kelly, E., 2003, Complex Systems and Evolutionary Perspectives on Organisations: The Application of Complexity Theory to Organisations, Elsevier, Oxford.

Morgan, G., 1986, Images of Organization, London, Sage.

Parsons, T., 1951, The Social System, London, Routledge and Kegan Paul.

Parsons, T., 1968, The Structure of Social Action, London, Collier Macmillan.

Payr, S. \& Trappl, R. 2004, Agent Culture: Human-Agent Interaction in a Multicultural World. London, Lawrence Erlbaum Associates.

Peters, T. J. \& Waterman, R. H. 1982, In Search of Excellence, London, Harper and Row.

Richardson, K., Mathieson, G., Cilliers, P. 2000, 'The theory and practice of complexity science epistemological considerations for military operational analysis', in SysteMexico, 1:25-66.

Robertson, D.A., 2005, 'Agent-based models to manage the complex', in K.A. Richardson (Ed.), 
Managing Organisational Complexity: Philosophy, Theory and Application, Information Age Publishing, Charlotte, NC, ISBN: 1-593-113-188, 419-432.

Rooke, J., Seymour, D. and Fellows, R., 2004, 'Planning for claims; an ethnography of industry culture', in Construction Management and Economics, 22(6):655-662.

Ryle, G., 1963, The Concept of Mind, Harmondsworth, Penguin.

Sacks, H., 1963, 'Sociological description,' in Berkely Journal of Sociology, 8:1-16.

Sacks, H., 1972, 'An initial investigation of the usability of conversational data for doing sociology', in D. Sudnow (Ed.) Studies in Social Interaction, New York, Free Press, 31-74.

Schutz, A., 1962, The Problem of Social Reality, The Hague, Marinus Nijhoff.

Seese, D., Schlottman, F. 2003, 'The building blocks of complexity: a unified criterion and selected applications in risk management', in Modeling, Computing and Mastering Complexity Series, Paper 14, Society for Computational Economics.

Shen, W., Norrie, D. and Barthers, J. 2001, Multi-agent Systems for Concurrent Intelligent Design and Manufacturing, New York, Taylor and Francis.

Smallwood, J., 2000, 'Contractor performance: clients' perceptions', in A.B. Ngowi and J. Ssegawa (eds), Challenges Facing the Construction Industry in Developing Countries, Proceedings of the 2nd International Conference of the CIB Task Group 29 (TG29) on Construction in Developing Countries, November, CIB, Gaborone, Botswana, 128-138. 
Snowden, D., 2002, 'Complex acts of knowing: paradox and descriptive self-awareness', in Journal of Knowledge Management, 6(2):100-111.

Stacey, R.D., 2001, Complex Responsive Processes in Organizations: Learning and Knowledge Creation, Routledge, London.

Steeb, W.-H., 2005, The Nonlinear Workbook, 3rd edn, World Scientific, London.

Strauss, A., Schatzman, L., Bucher, R., Ehrlich, D. and Sabshin, M., 1964, Psychiatric Ideologies and Institutions, New York, The Free Press of Glencoe.

Thomassen, M.A., Sander, D., Barnes, K.A. and Nielsen, A., 2003, J. C. Martinez \& C. Formoso (Eds.) 'Experience and results from implementing lean construction in a large Danish contracting firm', in Proceedings of the 11th Annual Conference on Lean Construction, July, Virginia Tech, Blacksburg, Virginia, 73-85. http://strobos.cee.vt.edu/IGLC11/PDF\%20Files/54.pdf

Vakili-Ardebili, A. and Boussabaine, A.H., 2007, 'Application of fuzzy techniques to develop an assessment framework for building design eco-drivers', in Building and Environment, 42(11):37853800.

von Neumann, J., 1966, Theory of Self-Reproducing Automata, London, University of Illinois Press.

Weber, M., 1976, The Agrarian Sociology of Ancient Civilizations, NLB, London.

Wittgenstein, L., 1958, Philosophical Investigations, Oxford, Blackwell.

Wolfram, S., 2002, A New Kind of Science, Illinois, Wolfram Media. 